\title{
Educación para la ciudadanía en el nuevo orden mundial
}

Walter Fernando Pérez Niño*

"Cada vez que nos preguntamos qué educación queremos, lo que nos estamos preguntado es qué tipo de mundo queremos fortalecer y perpetuar"

William Ospina.

\section{INTRODUCCIÓN}

La educación siempre ha tenido una relación con la realidad; desde un inicio su tarea ha sido explicar los distintos fenómenos sociales, naturales, culturales, etc., y desde allí abrir perspectivas que permitan comprender el mundo. Educar, entonces, es un aspecto determinante toda vez que, además de consolidar los saberes básicos, inserta valores, principios y actitudes en la sociedad.

En cada tiempo la educación ha tenido un papel relevante en la sociedad; con Esparta y Atenas se resaltaban los valores de la guerra, considerados apropiados para las recurrentes amenazas de ataques externos; en el feudalismo la educación era utilizada para explicar las realidades desde la religión y de acuerdo a la hegemonía de la iglesia; y con la modernidad se ha pensado la educación desde la razón y la cientificidad empero también dándole un enfoque beneficia a la clase burguesa (PONCE, 1974, p. 22-158). Así, es claro que también la educación no ha sido ajena a las relaciones de poder, algunas veces subyugándose a los más poderosos, adoctrinando y cimentando el statu quo; otras fungiendo como arma que sirve para doblegar las hegemonías imperantes.

Con la modernidad también se desarrolló la concepción de ciudadano que rompió los paradigmas que le antecedían, según los cuales, las personas no tenían cuando menos algunas garantías básicas o el derecho a participar. El ciudadano moderno es titular de un catálogo de garantías fundamentales y por tanto es visto como un sujeto de derecho y de deberes, es en un verdadero actor en la vida política

* Doctorando en Derecho, Universidad Autónoma de Chile. Magíster en Derechos humanos, Universidad Pedagógica y Tecnológica de Colombia (UPTC). Profesor Derecho Político y Derecho Constitucional, Universidad Autónoma de Chile. Correo electrónico: w.perez@uautonoma.cl. 
en la medida en que se le reconoce la capacidad de intervenir en la administración del Estado y por tanto tomar partida en las decisiones que lo afectan.

Educación y ciudadanía se encuentran estrechamente relacionados. Por una parte los derechos de la ciudadanía permiten incorporar la educación como un derecho y un deber del estado y por otra, la educación enfocada en la ciudadanía, puede potenciar valores beneficiosos para el desarrollo de una sociedad, democrática, participativa, interesada en los problemas de la comunidad.

Sin embargo, la modernidad se ha agotado y nos encontramos frente a nuevas realidades; a un nuevo orden mundial, posmoderno y globalizado que cambia la dinámica de educación y de ciudadanía, como quiera que acompañado de dinámicas y realidades que cambian el panorama organizacional a que se venía acostumbrado.

Bajo ese panorama, en las siguientes líneas se hará una exposición de la relación educación para la ciudadanía y nuevo orden mundial, para lo cual, en primer lugar se explicará la concepción de nuevo orden mundial, presentado realidades que afectan las estructuras sociales actuales; luego de ello se hará un exposición sobre la educación y su especial relación con la ciudadanía en la actualidad y; finalmente, presentarán varios panoramas sobre la educación y la ciudadanía en el nuevo orden mundial.

\section{CIUDADANÍA Y NUEVO ORDEN MUNDIAL.}

\subsection{Ciudadano como sujeto de derechos}

Con el advenimiento de la modernidad se rompen algunos paradigmas relacionados con la educación y la ciudadanía abriendo horizontes que aún marcan nuestros ordenamientos actuales.

Con teóricos como Rousseau, Thomas Hobbes y John Locke se dieron las bases de la estructura de la teoría del contrato social. Según esta, los hombres le ceden al Estado una fracción de sus derechos con el propósito de que este administre la sociedad propendiendo por el bien común; dentro de esta óptica, fuertemente marcada por el iusnaturalismo, se entiende que cada persona tiene derechos naturales que son comunes a todos los hombres, radicados principalmente en la libertad e igualdad formal.

La importancia de esta teoría se refleja en el cambio del tipo de responsabilidad con el pueblo en el Estado monárquico y ulteriormente en el Estado liberal. En el absolutismo, la concentración de poderes en el rey estaba legitimada en Dios, por lo que solamente se debía rendir cuentas a él; al contrario, con la teoría moderna, el poder se legitima en la ciudadanía que a cambio de una porción de sus derechos compromete al Estado a responder por sus actos. 
El desarrollo del concepto de ciudadano cambia su rol, ya no es visto como un simple vasallo, sino como un componente importante del Estado y en definitiva como un sujeto de derechos. Así este se describe como:

El elemento nuclear de la articulación de las relaciones entre política y derecho en los Estados nacionales. No en vano ese status de ciudadano vino a abrogar, definitivamente, la estratificación estamental de las sociedades del antiguo régimen en beneficio del reconocimiento de la igualdad jurídica de todos los individuos, con independencia de su origen social o de su posición económica (JULIOS-CAMPUZANO, 2003, p. 37-38).

Sin embargo, no debe pasarse por alto que la ciudadanía en los primeros Estados modernos estaba asociada con un concepto de clase burguesa que trajo consecuencias en la realización de los derechos que actualmente se entienden intrínsecos del ser humano:

En efecto, el ejercicio de estos derechos a través de la participación democrática no siempre estuvo atado al concepto de ciudadano sino que se dio paulatinamente. Los primeros Estados liberales restringían la participación electoral. En Francia, pese a que la normatividad reconoció derechos "del hombre y del ciudadano", el ejercicio de los derechos de la ciudadanía era limitado, de esa forma el sufragio no estaba establecido para las colectividades de escasos recursos económicos ${ }^{12}$. Ese, es un ejemplo de una tendencia que fue replicada en las primeras cartas de Latinoamérica ${ }^{23}$. Fue con posterioridad, especialmente en la segunda parte del siglo XX, que estos derechos se lograron establecer dentro de los ordenamientos, cuando por fin fueron otorgados a sectores excluidos como mujeres y afrodescendientes ${ }^{34}$.

Así mismo, la implementación de la ideología burguesa tuvo repercusiones en la amplitud de derechos reconocidos a los ciudadanos, los cuales, son de corte liberal. En consonancia con lo anterior, el Estado se caracterizó por no realizar intervención alguna, permitiendo el ejercicio abusivo de las relaciones laborales por parte de los dueños de los medios de producción en detrimento de las clases obreras que se vieron relegadas a trabajos marginales con jornadas excesivas y un salario insuficiente para sufragar gastos básicos. En ese sentido, la conquista de derechos sociales significó el cambio enfoque hacia un Estado capaz de regular las relaciones privadas y prestar los servicios básicos, cambiando su rol a un Estado activo e interventor (BARZELATO; VERDUGO, 2011, p. 138-141).

Desde allí se empieza a entender un concepto distinto del ciudadano que no abarca solamente el modelo burgués es decir: hombre, mayor y acaudalado, sino se amplía para comprender a la mayoría de las personas fijándose requisitos menos estrictos como cumplir la mayoría de edad. 
De igual manera, en consonancia con la evolución normativa también cambia el catálogo de derechos del ciudadano incorporándose los derechos sociales los cuales adquirieron una dimensión normativa de manera paulatina, siendo ejemplos de inicio de ese avance las cartas de México de 1917 y Weimar de 1919.

El concepto de ciudadano desde entonces se encuentra ligado al de sujeto de derechos, los cuales varían dependiendo de la época histórica como se viene exponiendo. Lo que es claro es que su desarrollo siempre ha estado encausado a la apertura de derechos y la capacidad de los ciudadanos; por eso, en armonía con su desarrollo, debería seguirse ampliando la lista de derechos protegidos y la capacidad de intervención política de los ciudadanos dentro de los límites de la democracia.

\subsection{Nuevo orden mundial}

Chomsky muestra que naciones como Estados Unidos y Gran Bretaña desde la segunda mitad del siglo XX especialmente se han encargado de intervenir en la autonomía de los países para introducir ordenamientos acorde a sus intereses de dominación. Esto a partir de dos frentes: la intervención militar y la economía.

Así, Gran Bretaña ejerció poder dentro de otras naciones destacándose su intervención en India y Estados Unidos desplegó sus fuerzas armadas en países como Kuwait y Vietnam, y ante la imposibilidad de abarcar militarmente a América Latina cooptó a las fuerzas armadas y patrocinó dictaduras (CHOMSKY, 1991, p. 15-20)

Dicho manejo se dio dentro de la llamada doctrina de seguridad nacional (BUITRAGO, 2003, p. 74-87), que buscaba controlar cualquier ideología de carácter socialista o comunista de Latinoamérica, dentro del contexto de la guerra fría en el que dichos pensamientos se asociaban a una presunta amenaza para la libertad materializada en el régimen comunista de la URSS.

En Chile, particularmente, la injerencia estadounidense utilizó el poder sobre las fuerzas militares para introducir el modelo económico neoliberal, inclusive antes que las dos potencias mencionadas.

El fin de la guerra fría significó un gran cambio (ORTIZ, 2022, p. 123), se rompe la bipolaridad y las potencias de occidente pueden seguir extendiendo su hegemonía por el globo. Sin embargo Chomsky (2001, p. 24) enfatiza que esta circunstancia no representa un gran cambio porque desde antes Estados Unidos se había consolidado como un imperio, inclusive desde la misma doctrina Monroe.

Ese poder también se reorganizaría años después en el medio oriente, como consecuencia de los atentados a Estados Unidos el 11 de Septiembre de 
2011, acontecimiento que también es tomado como punto de partida para hablar de un nuevo orden mundial (ROIG-IBÁÑEZ, 2006, p. 1-22).

Teniendo en cuenta los antecedentes hegemónicos de occidente si bien resultan en cambios importantes en la geopolítica global, no se pueden tomar como la constitución de un nuevo orden mundial ya que tales cambios no rompen ningún paradigma sobre la organización global, sino que dejan ver el afianzamiento de un modelo de dominio que se venía implementando desde inicios de siglo.

Lo que si se puede afirmar, es que desde 1990, se sofisticó la estrategia económica como forma de dominio. La doctrina neoliberal experimentada en Chile en la década de los noventas se globalizó junto con sus políticas relativas a la disciplina fiscal, reducción de gasto público, reformas tributarias para ampliar el número de contribuyentes, privatización de empresas estatales y desregulación de la economía, en sus primeros años. Luego, a consecuencia de la crisis económicas asiática de 1997 se impondrían otro paquete de medidas como la flexibilización laboral, la fortificación de las instituciones que supervisaban el mercado y políticas sociales focalizadas (RODRÍGUEZ GARAVITO, 2008, p. 25-26). Esto trae una consecuencia importante dentro de la dinámica global. La liberalización de capitales provoca que las empresas transnacionales adquieran relevancia dentro de los Estados nacionales. El poder económico de estas se convierte en un factor preponderante para influir los gobiernos locales, mediante el establecimiento de leyes y políticas públicas que les favorecen. La inversión extranjera se vende como un elemento positivo que dinamiza la economía y fomenta el empleo, a partir de esas justificaciones se instauran las políticas neoliberales que dan estas empresas seguridad jurídica y beneficios tributarios.

Además de ello el domino hegemónico también se ve reflejado en los Organismos Internacionales multilaterales. Chomsky (1996, p. 17-43), muestra que, por ejemplo, en la conformación de la Organización de Estados Americanos se concedió un poco de libertad por parte de Estados Unidos a los países que la conforman, esto se encontraba supervisado para que los países no se sobrepasaran en el principio de la no intervención. A la par, también se encuentran Organizaciones de índole internacional como el Banco Mundial y el Fondo Monetario internacional que constantemente promueven y supervisan el cumplimiento de las políticas neoliberales.

De tal manera que los Estados Nacionales se encuentran constreñidos por las naciones que han detentado el poder de manera hegemónica, las empresas trasnacionales y algunos organismos internacionales. Todo ello asegurado y supervisado en lo militar, para ello, Estados unidos y la OTAN cuentan con bases armadas por el mundo incluyendo zonas estratégicas de América Latina.

El nuevo orden mundial no es tan reciente como se pretende afirmar, más bien sobre este han existido reformas fruto de acontecimientos históricos que le han permitido su expansión y sofisticación en la implementación, pues como se ha 
dicho, desde hace bastante tiempo se ha desarrollado y asentado el dominio de las potencias económicas a través de las armas y el sistema económico, destacándose en la actualidad el nivel de recepción por parte de los Estados del globo, a partir de la ruptura de la bipolaridad, de las doctrinas neoliberales, cuyo desarrollo ha empoderado a las empresas transnacionales ý organismos internacionales de índole económico para ejercer una gran influencia en la imposición de políticas nacionales acorde que les favorezcan en el marco de la doctrina neoliberal.

No obstante lo expuesto hasta ahora, si puede considerarse que un nuevo orden mundial se está gestando. La hipercomplejidad de las relaciones internacionales ha surtido nuevas alianzas entre países donde se destaca el desempeño de China como un actor económico preponderante no solamente conformando el nuevo bloque económico conocido como los BRICS donde hacen parte también potencias emergentes como Brasil, Rusia, india y Sudáfrica, sino también ofreciendo alternativas a la economía hegemónica financiera liderada por el FMI y el BM. (CONTIPELI; PICCIAU, 2014, p. 26-39)

\subsection{Ciudadano en el nuevo orden mundial.}

Como vemos en el orden mundial imperan las ordenes de los Estados hegemónicos, organismos económicos multilaterales y los grandes capitales, los cuales culminaron con la implementación casi que a escala global de las disposiciones del modelo neoliberal, junto con sus medidas de austeridad en el gasto social, la desregularización de la economía, fomento a la inversión y libertad de los capitales extranjeros, y apertura al libre comercio.

El establecimiento de sistemas democráticos es casi un paradigma de los Estados contemporáneos, que reconocen a estos como medios idóneos en los que se realiza el ser humano. La importancia de estos tipos de sistemas realza el papel del individuo frente al Estado, no es suficiente la consagración normativa de derechos sino que es preciso en el ámbito de la libertad que los pueblos puedan gobernarse y así ejercer el derecho a la autodeterminación.

La imposición del modelo neoliberal cercena la autonomía de los Estados toda vez que las políticas de esta no está sujetas a la discusión democrática (JULIOS-CAMPUZANO, 2003, p. 47), esto sin duda consiste en una afrenta a la efectividad de los derechos del ciudadano, la participación política y los derechos reconocidos.

Los derechos ciudadanos a elegir y ser elegidos dentro de esta lógica sufren una gran limitación en primer lugar el acceso al poder está condicionado por aspectos económicos donde los patrocinios de grandes capitales privados juegan un rol fundamental para la consecución de los objetivos electorales. Los candidatos con pequeños apoyos económicos no pueden competir con aquellos que poseen un financiamiento alto, los cuales generalmente llegan a los cargos 
de poder y en concordancia con los respaldos recibidos siguen las lógicas de la estructura económica impuesta.

La creación de una "clase dirigente" afecta la participación ciudadana. La solidificación de castas políticas que se van rotando en los cargos preponderantes del Estado y qye no atiente satisfactoriamente el bien común desliga a los pueblos del Estado. Se ve una apatía en relación con los derechos ciudadanos y políticos toda vez que en ellos no se observa un cambio de los parámetros de gobierno independientemente de quien gane las elecciones.

También se sufre un menoscabo en los derechos reconocidos y no solamente frente a los de la ciudadanía que, como se viene diciendo, parecieran volverse ficticios en relación con su efectividad en un cambio social. El dominio de estas políticas neoliberales sostenidas por la dirigenciarepercute en un menoscabo de los derechos conquistados, en especial de los derechos sociales. Así la educación y salud han hecho tránsito de derechos sociales a servicios regidos bajo las reglas del mercado y por tanto su aseguramiento depende de la capacidad de pago. Las políticas de austeridad impactan las políticas sociales y por eso se sigue presentando desigualdades estructurales que se reflejan en algunos fenómenos como muertes por hambre o por enfermedades previsibles, trabajo infantil, etc. De igual forma la creación de figuras jurídicas para la flexibilidad laboral impiden estabilidad, salario digno, prestaciones justas, asociación sindical, etc., volviendo casi imposible la movilidad social.

Pero las políticas económicas no son las únicas que encuentran eco mundial, estas también hacen parte del proceso complejo de la globalización, que comprende otros aspectos. Así la globalización puede ser entendida como:

[U]n proceso económico, tecnológico, social y cultural a gran escala, que consiste en la creciente comunicación e interdependencia entre los distintos países del mundo unificando sus mercados, sociedades y culturas, a través de una serie de transformaciones sociales, económicas y políticas que les dan un carácter global (MEJÍA; DELGADO; VALVERDE, 2014,p. 17)

En el mismo enfoque, para Bauman (2001):

[G]lobalización significa que todos dependemos ya unos de otros. Las distancias cada vez importan menos, lo que suceda en cualquier lugar, puede tener consecuencias en cualquier otro lugar del mundo (...) hemos dejado de poder protegernos tanto a nosotros como a los que sufren las consecuencias de nuestras acciones en esta red mundial de interdependencias

De lo anterior se colige que nos encontramos insertos en una dinámica global que abarca más que los poderes económicos e incluye aspectos sociales, 
culturales y tecnológicos. En estas últimas décadas se ha notado un gran avance en las tecnologías de la información y la comunicación, que facilitan la creación de redes sociales y de información, y la comunicación de manera inmediata con cualquier parte del globo, por esto desde hace unos años es posible conocer casi inmediatamente cualquier acontecimiento relevante sin importar el lugar en que se produzca.

La globalización vuelve hipercomplejos los problemas existentes y crea algunos nuevos, la ciudadanía tiene que afrontar los problemas relatados concernientes a la reducción de la participación efectiva, pero además a algunos otros que trascienden mucho más allá de las fronteras, como el calentamiento global y la migración.

Es decir que en la actualidad nos encontramos en una nueva etapa histórica: la posmodernidad, caracterizada por la complejidad de las relaciones entre los distintos agentes, la fragmentación de la sociedad, la deslegitimación de la historia como único relato y la mezcla de culturas (MICHINEL ÁLVAREZ, 2012, p. 21-22)

Estas nuevas circunstancias dejan ver claramente que los problemas han alcanzado dimensiones grandes e intrincadas que dejan ver la incapacidad de los estados nacionales para solucionarlas (JULIOS-CAMPUZANO, 2003, p. $40)$, Esto por lo menos de manera individual.

Dentro de estos problemas de nivel mundial la migración es importante ya que se relaciona estrechamente con la idea de ciudadanía. Desde hace un tiempo los sistemas de normas en los países con desarrollos económicos buenos adoptan, por regla general, políticas legislativas para restringir el ingreso de migrantes de países pobres o limitar e goce y ejercicio de derechos. Esto sin lugar a dudas constituye un retroceso en la construcción de una ciudadanía como sinónimo de sujetos dederechos, negando en aquellos seres humanos el atributo de la dignidad que se desarrolló en el reconocimiento de ciertas garantías propias de su persona. Estas limitaciones sin duda consisten en una negación del carácter de ciudadano de la persona o cuando menos en una categorización de estos, contrariando el derecho a la igualdad.

A lo anterior debe sumarse un elemento cultural, con frecuencia los inmigrantes son víctimas de conductas xenófobas. En el imaginario social son vistos como como inferiores y asociados a actividades delictivas. En ese sentido se han creado organizaciones extremistas con ideologías fundamentadas en una superioridad nacionalista o racial que actúa en contra de estas comunidades. También, desde la política también se articulan discursos que atribuyen los fenómenos de crimen o desempleo a las poblaciones de inmigrantes ${ }^{45}$. En general se crea un clima de hostilidad en contra de estas personas.

De esa manera, en consonancia con el desarrollo político, económico, social y cultural, es preciso desarrollar un concepto de ciudadanía evolucionado 
que se concrete en un reconocimiento de los derechos de las personas como sujetos de derecho capaces de decidir en la manera en que la sociedad de que hacen parte debe ser administrada. Por ello es necesario replantear concepciones que cierran el concepto de ciudadanía determinado a ciertos aspectos excluyentes que redundan en el socavamiento de los derechos humanos universales y encaminarse a un sentido de ciudadanía dentro del ámbito de una solidaridad global.

Por otra parte, la globalización también ha mostrado que existe una pluralidad de grupos e individuos inconformes con ese orden económico y social que ha sido forzado. La posmodernidad también ha permitido un entramado de relaciones complejas en las que interactúan movimientos sociales, Organizaciones No Gubernamentales, individuos, etc., quienes a través de distintas acciones de protesta y manifestaciones en las redes sociales, se expresan en contra de las consecuencias del orden económico imperante, desplegando con ello un ejercicio de ciudadanía política mundial que se muestra como una alternativa para contrarrestar o por lo menos pronunciarse en contra del orden global injusto.

Sin embargo, esos escenarios de resistencia internacional parecen insuficientes ya que los problemas se siguen expandiendo. Es necesario entonces una respuesta efectiva por parte de los Estados y Organismos Multilaterales. En ese contexto, la participación ciudadana tiene que fortalecerse para encontrar soluciones a las problemáticas actuales. Una experiencia esperanzadora es el activismo social que se ha dado utilizando las herramientas de justiciabilidad de los derechos y como esta ha venido sacando provecho de escenarios como las Cortes Interamericana, Europea y Africana de Derechos Humanos.

Así, desde la participación debe seguir construyendo soluciones para las problemáticas estructurales que permitan revalidar y ampliar el concepto de ciudadanía a partir de principios y valores como libertad, igualdad, dignidad humana y solidaridad, todo ello dentro de la participación democrática.

No existen soluciones universales a las problemáticas actuales, por el contrario la misma ciudadanía debe validar su condición y proponer dentro del ámbito de la democracia alternativas para la conservación, ampliación y efectividad de los derechos.

\section{DERECHO A LA EDUCACIÓN Y CIUDADANÍA}

Aristóteles en su libro Metafísica señaló que "todos los hombres tienen naturalmente el deseo de saber" con ello denotando esa necesidad del ser humano de encontrar razones que expliquen el mundo que lo rodea y métodos que le hagan mejorar la calidad de vida.

Es la educación el proceso encaminado a trasmitir los conocimientos y desarrollar las herramientas para suplir los deseos intrínsecos de las personas y 
seguir avanzando en ellos para la construcción de un avance científico, social y cultural.

En tanto histórico, la educación se ha trasformado acorde a los contextos particulares de cada etapa, dentro de ello las relaciones con el poder. De hecho este ha sido significante para su desarrollo en la medida en que sus intereses la han permeado dándole un sentido. Así, la educación se ha utilizado en la antigüedad para fortalecer los valores de la guerra, en la edad media para instalar el dogma religioso y en la modernidad hacia la búsqueda de una verdad desligada de la religión pero a fin a los valores liberales burgueses (PONCE, 1974, p. 22-158)

$\mathrm{Al}$ derrocarse el absolutismo la nueva organización social se encuentra frente al reto de consolidación del concepto de ciudadano como un elemento que permita crear una identidad propia, y una suerte de historia común que fortalezca los lazos sociales y que sustituya a la figura del rey ${ }^{56}$ como componente común de unión.

La educación moderna se encargó de modificar las concepciones de los individuos a fin de que asumieran su nuevo rol de ciudadano en la comunidad política. De esa forma incorporó relatos y elementos de identificación común ${ }^{67}$ para afirmar un sentimiento de pertenencia con una comunidad a través de la creación de una cultura colectiva.

Pero la educación moderna también cambia otros paradigmas. El movimiento de la ilustración impacto la esfera del conocimiento estableciendo a la razón como principal criterio para buscar la verdad, desvinculando a la religión católica predominante como fundamento fenomenológico, así, la educación se aleja de la religión al buscar respuestas sobre el mundo a partir de la ciencia.

Aunado a lo anterior, también se intentó desligar la religión de la educación moral y ética pública con la paulatina incorporación la laicidad entendida como la neutralidad e independencia que debe guardar el Estado (CONTIPELLI, 2013, p. 14). Esto se traduce en que la educación a cargo del Estado no debe incluir enseñanzas orientadas al adoctrinamiento religioso ${ }^{78}$. Valga aclarar que la educación laica es relevante porque contribuye a la formación de una ciudadanía plural y tolerante de las ideas de lo demás, aspecto de principal relevancia en la actualidad teniendo en cuenta el fenómeno migratorio descrito en párrafos que anteceden.

Por otra parte, también debe tenerse en cuenta que aunque la educación no fue reconocida como derecho en los primeros Estados modernos el constitucionalismo desarrollado en estos por el cual se aseguraron los derechos liberales, sirvió como elemento de garantía para su posterior conquista como consecuencia de las luchas obreras y populares. De esa manera, la educación fue incorporada dentro en los ordenamientos constitucionales desde la primera parte del siglo $\mathrm{XX}^{898}$ siendo reiterado inclusive en las últimas décadas en países como Brasil, Argentina, Colombia, Ecuador, Perú, Bolivia, México, Venezuela y Ecuador 
dentro del llamado "Nuevo Constitucionalismo Latinoamericano"(RODRÍGUEZ, 2008, p. 36-44).

También en el ámbito internacional se expidieron textos jurídicos que acogieron este derecho como la Declaración Universal de Derechos humanos y el Pacto Internacional de Derechos Económicos Sociales y Culturales. Se puede considerar entonces que existe un marco jurídico solido que establece la educación como un derecho cuando menos en noveles básicos.

Así, la modernidad deja un legado en cuanto a la educación como derecho y su papel dentro de la formación de ciudadanos titulares de derechos relevante en esta época posmoderna de hipercomplejidad de las relaciones entre los distintos sujetos sociales.

Ahora bien, con el paso a la posmodernidad se encuentra un contexto relacional más complejo que compromete a la educación y la ciudadanía dentro de lo económico, tecnológico, social, cultural, normativo y político, entre otras.

Así, dentro de lo económico, la globalización del sistema económico neoliberal ha disminuido las políticas sociales (DIAZ; MULLER, 2006, p. 127-128), las empresas públicas prestadoras de derechos sociales fueron privatizadas y la política de austeridad presiona cada vez más para la disminución de recursos destinados por los Estados para su satisfacción. La doctrina económica ha privatizado los derechos toda vez que el Estado se ha despojado de sus responsabilidades y las deja en manos de actores privados los cuales realizan sus actividades con fines de lucro, con ello desnaturalizando sus derechos y sometiéndolos a otra lógica que más que preocuparse por su efectivo aseguramiento se asegura de sacar provecho económico de los mismos, situación que puede redundar en vulneraciones. Privatizar los derechos, especialmente los sociales, es doblegarlos ante el sistemaeconómico.

En el ámbito tecnológico hay un gran avance que permite el fácil acceso a la información e intercambios con las demás culturas. Esta red ofrece información inmediata de los acontecimientos que pasan en el mundo, fue así como se dieron a conocer los distintos levantamientos en la denominada Primavera Árabe o el Movimiento de Indignados en España, y con ello se vio un desarrollo del ejercicio de la ciudadanía que influyó en otros movimientos sociales; la internet potencia la opinión de los ciudadanos sin ningún filtro, siendo posible tener una experiencia en relación con la percepción de las personas frente a las realidades actuales; también hace posible el intercambio rápido de datos y el afianzamiento de lazos de colaboración de movimientos trasnacionales y de ONG's. Particularmente en el ámbito educativo el internet posee una enorme fuerte de información facilitando el acceso al conocimiento pues rompe barreras físicas, geográficas o económicas que otrora truncaban el acceso a obras literarias; abre además vías para acceder a otras culturas y en esa perspectiva permite entenderlas, propiciando un mejor ambiente de tolerancia.

En la parte social, los intercambios migratorios repercuten en que el perfil del ciudadano. Este ya no posee las características observadas en el apogeo de los Estados nacionales, es decir un ciudadano adscrito a componentes culturales como idioma y religión determinados y mayoritarios que permitían determinar un perfil de nacionalidad claro, con unos sentimientos patrios establecidos. El ciudadano en el contexto en la posmodernidad y la globalización es producto de todos los intercambios culturales. La apertura de nuevos canales de comunicación 
implica una formación personal influenciada por manifestaciones culturales musicales, televisivas, radiales etc., de otros países con diferentes enfoques, ello hace que sus apropiaciones culturales no sean las convencionales y se diversifiquen casi de manera individual dependiendo del acceso a la información e influencia en cada uno de los sujetos.

En el ámbito social, de igual manera la migración crea un ambiente educativo complejo. El migrante se presenta en otros escenarios culturales ajenos que tiene que asimilar presentándose una batalla entre sus tradiciones y las del nuevo contexto ${ }^{910}$. En ese sentido, la educación es un elemento preponderante para la convivencia pacífica y multicultural en la medida que se promuevan valores de pluralidad y tolerancia.

En relación a lo normativo, los ordenamientos jurídicos tienen que adaptarse a esa nueva realidad cosmopolita y en esa medida garantizar legislar reconociendo estos derechos dentro de un marco de pluralidad.

Dentro de lo político, los Estados se deben asegurar a través de las políticas condiciones asequibilidad, accesibilidad, aceptabilidad y adaptabilidad (TOMASEVSKY, 2004, p. 77-79), para el goce del derecho a la educación. Esto se traduce en que el sistema educativo debe incorporar sin ningún tipo de discriminación a las personas dentro del marco de los compromisos adquiridos y proporcionar un servicio que tenga en cuenta aquellas diferencias culturales y nuevas realidades, adaptándose a cada contexto.

En conclusión, educación y ciudadanía se encuentran estrechamente relacionados, si tenemos en cuenta que un concepto amplio de ciudadanía pluricultural permite el goce del derecho a la educación dentro de condiciones que permitan el respeto por la diversidad y a su vez la educación en la ciudadanía fomenta valores de respeto, entendimiento y tolerancia en la diversidad.

\subsection{Educación para la ciudadanía en el nuevo orden mundial}

Al estarligada ala realidad, la educación obedece a ese nuevo orden mundial exhibiendo una multiplicidad de problemas, de acceso, contenido, adaptabilidad, entre otros, los cuales serán presentados a continuación, acompañados de algunos criterios que debe implementar la educación para la ciudadanía en el nuevo orden mundial.

\subsection{Problemas de inequidad}

En la actualidad la educación se sigue presentando las mismas inequidades que ha desplegado en casi toda la historia, inclusive de una forma más honda. En los ámbitos locales se siguen dando inequidades reflejadas en diversos tipos de educación que depende de la capacidad de pago asegurando la existencia de elites 
formadas para gobernar y una formación popular para la ocupación de cargos medios y bajos.

Sumado a lo anterior, estas desigualdades en la educación no solamente se ciñen a los planos nacionales sino que se potencializa a un disparidad internacional. Existe una división internacional de la educación. Los centros educativos que desarrollan ciencia y tecnología se aglutinan en los países de poder hegemónico, aplicando este desarrollo en la industria y de esta manera potenciándola en el globo. Al contrario, las políticas de austeridad de los países sometidos a las políticas neoliberales, no desarrollan conocimientos científicos que puedan aprovechar para generar una industria propia, estando así condenados a seguir siendo proveedores de materias primas.

\subsection{Problema de progreso y educación}

Ahora bien, la educación es percibida como un factor de desarrollo y movilidad social, y aunque esta se ha masificado gracias a los compromisos asumidos por los Estados, no han resultado en mejor calidad de vida para las personas que deciden realizar una carrera profesional. Los recién egresados, en su mayoría jóvenes, afrontan a una realidad de desempleo y falta de oportunidades; pero el panorama no mejora al conseguir trabajo ya que se tiene que acoger a condiciones laborales precarias, que con figuras como la tercerización laboral, no les ofrece estabilidad ni retribución justa. Así las cosas, la educación en los términos que se desarrolla y en las condiciones sociales dentro de las que se mueve, no cumple sus objetivos de progreso.

Dicho panorama termina cercenando sus derechos a la ciudadanía, ya que muchos de estos recién egresados terminan haciendo parte de sistemas clientelistas. Por conseguir una oportunidad de trabajo estos terminan sacrificando sus derechos de participación política, en tanto no ejercen el derecho al voto de acuerdo a sus convicciones personales enfocadas en el bien común sino como pago por tener una oportunidad para desempeñar su profesión.

\subsection{Problemas de acceso a la educación}

En relación con el acceso, se pueden entrever 3 problemas actuales que lo impiden por un lado existen barreras económicas estructuradas, pues por ejemplo así existan gratuidad en cuanto a matricula, los niveles de pobreza son tan elevados que cualquier costo adicional como de transporte se torna una carga impagable.

En segundo lugar están las preconcepciones culturales que generalmente dentro de visiones patriarcalistas marginan a la mujer de la educación condenándola a asumir las funciones del hogar, situación que perpetúa su indefensión e independencia. 
En tercer lugar se encuentra el problema de falta de educación o educación apropiada a distintos grupos que merecen una atención especial como las personas con algunas discapacidades físicas o cognitivas, aquellas superdotadas o con capacidades excepcionales y otras con diferentes perspectivas culturales como los pueblos indígenas.

\subsection{Problemas de adaptabilidad}

Sobre adaptabilidad también existen problemas derivados de las divergencias culturales. Los migrantes cuando pueden acceder al sistema educativo se encuentran con barreras como la del idioma que pueden ser un impedimento para el aprendizaje pues no han desarrollado. Por ello, asegurar su ingreso consiste solamente en una etapa que no necesariamente garantiza su correcta formación.

Este problema también se puede hacer visibles en contextos estatales multiculturales con los pueblos indígenas que requieren una etnoeducación conforme a sus visiones y valores ancestrales por lo que la proporción de una educación típica entra en conflicto con su identidad.

\subsection{Problemas de aceptabilidad}

En referencia a aceptabilidad, la calidad educativa brindada por los países pobres sobre todo en el ámbito público no es la mejor, los colegios públicos obtienen bajos resultados especialmente en las zonas rurales denotando con ello una carencia respecto a conocimientos básicos. No se asegura entonces para los sectores vulnerables una educación de calidad perpetuando así su situación de marginación.

\subsection{Enfoque de la educación hacia el nuevo orden mundial}

Teniendo claros algunos de los principales problemas que aquejan la educación en este orden mundial actual, es más fácil visualizar cual es el papel que debe desempeñar la educación para la ciudadanía en un sentido amplio. Por ello no se debe perder de vista que:

[L]a ciudadanía está relacionada también con la capacidad de personas y colectivos para convertirse en actores de lo público, de tal manera que los derechos humanos y los derechos fundamentales no estén presentes sólo en la órbita jurídico- política del Estado, sino que se realizan también a través de la acción y las luchas sociales desarrolladas por las personas y colectivos para gozar de sus derechos políticos y sociales (OBSERVATORIO PROGRAMA PRESIDENCIAL DE DERECHOS HUMANOS Y DIH, 2009, p. 16) 
De tal manera que la educación para la ciudadanía debe estar encaminada al reconocimiento y respeto de los derechos propios y de los otros, así como el ejercicio de la participación dentro del ámbito de la democracia. El principal objetivo entonces de la educación para la ciudadanía es potenciar la capacidad de los individuos frente a los Estados para la efectiva realización de los derechos humanos a través de la participación por los mecanismos institucionales y democráticos.

A partir de allí la educación de la ciudadanía en primer lugar debe solucionar los problemas de fondo que impiden la realización de la educación de la ciudadanía y proporcionarla con un enfoque que permita afrontar los problemas emanados del orden imperante para ello debe:

- Replantear el papel de la escuela frente al trabajo, articulando una formación que permita e empleo de las personas, sin que sea ese su único objetivo, con políticas sociales para la incorporación de jóvenes a las actividades laborales (TEDESCO, 2000) dentro de un marco de dignidad.

- Conectar la educación con la creación de ciencia y tecnología, para ello debe fomentar la investigación encaminada a encontrar métodos para el progreso de la industria frente al aprovechamiento sostenible de los recursos naturales.

- Propender por la igualdad y por lo tanto no crear tipos de educaciones dependiendo de la capacidad económica de las personas. Para ello debe mejorar la calidad educativa especialmente en las zonas rurales.

- Diseñar una institucionalidad tendiente a satisfacer las necesidades educativas delas personas discapacitadas o superdotadas (ROIG-IBAÑEZ, 2006, p. 440-441), así como a las indígenas, ya que la masificación de la educación ha logrado excluirlos. De esa forma la prestación del derecho educativo público debe preocuparse de disponer centros especiales para este tipo de personas pues generalmente la educación especial se encuentra en manos privadas lo que hace subsume este derecho a la capacidad económica.

- Armonizar las disposiciones en materia educativa, lo anterior quiere decir que al implementarse políticas públicas educativas, debe tener en cuenta las disposiciones de derecho interno y las de derecho internacional, entre ellas las recomendaciones de actores como el Comité de Derechos Económicos y Culturales, y la OCDE.

Centrado en la educación para la ciudadanía particularmente esta debe:

- Estar abierta a las culturas minoritarias y fortalecer el respeto por la diversidad de ideas y de tradiciones, siendo enfática en el rechazo de toda conducta tendiente a la intolerancia y/o xenofobia. 
- En con concordancia con lo anterior, generar una identidad lo suficientemente fuerte para que las personas conozcan y valoren su cultura, pero encauzada a la fraternidad para que no sea vista como superiora las demás, sino como un parte de un mundo cosmopolita que debe ser respetado.

- Aportar las bases necesarias para que pueda vivir en comunidad y ser respetuoso de las normas, pero también debe educar para que las personas sean conscientes de su calidad como sujetos de derecho portadores de la dignidad humana capaces de hacerla valer en escenarios de vulneración normativa.

- Educar en la pluralidad, promoviendo valores como el respeto, la tolerancia y la solidaridad entre todas las personas sin diferenciar raza, creencias, condición social etc.

- Fomentar la solidaridad como un parámetro transversal en la educación que más allá de la comprensión de las otras culturas para promover actitudes que fraternidad e integración cultural. Educar para la pluralidad

- Llevar la educación más allá del plano clásico de la escuela. Educar para una ciudadanía implica estar constantemente aplicando políticas de educación a través de otros medios como radio, televisión, conferencias, estrategias por redes sociales, etc., los cuales no necesariamente están dirigidos a las personas en edad escolar.

- Teniendo en cuenta lo anterior, desde la institucionalidad se debe promover campañas públicas que rechacen la discriminación y/o xenofobia.

- Asimismo propiciar ambientes de integración con los demás, pero sin afectar su sistema de creencias. También tiene que aportar hacia la tolerancia de manifestaciones personales de la sexualidad, como en el caso de parejas del mismo sexo.

- Velar por la "construcción de una ciudadanía intercultural" según la cual además de la estimulación conceptual esta se debe potencializar como un acto político. Así, la construcción de la ciudadanía debe también debe potenciar su pensamiento crítico, desarrollando las capacidades de diálogo y negociación, y los valores populares con observancia de otras culturas y trabajando en su liderazgo (FERNÁNDEZ, 2008, p. 205-210).

- "Empoderar a las personas para que sean sujetos de Derecho" (MAGENZO, 2003, p. 22) Lo que significa que debe otorgar los elementos necesarios para que las personas conozcan sus derechos y la manera en que estos pueden ser efectivos, sin dejar de lado también las obligaciones de respetar los derechos de las demás personas. 
- Incluir en los espacios de enseñanzas las nuevas tecnologías de la información y la comunicación (MEJÍA; DELGADO; VALVERDE, 2014, p. 15), para ello es conveniente que enseñe el manejo de tecnologías a los estudiantes, sino que incluya el manejo de estas como un todo en la cátedra, para que se aprendan a utilizar dentro de los contextos académicos, también siendo importante la capacitación de los docentes.

- De acuerdo al punto anterior, favorecer el acceso de los estudiantes a estas tecnologías para su uso en la vida cotidiana, esto amplía las perspectivas de los alumnos en relación con el mundo que los rodea al tener acceso al conocimiento de otras manifestaciones culturales y con ello abrir su percepción hacia la comprensión de otras manifestaciones culturales y entender de forma más abiertas los problemas del mundo.

- Propender por la integración de la mujer de manera efectiva a los sistemas educativos, y en esa medida tratar de remediar un poco el estado de desigualdad en que ha estado (LEIS, 2005, p. 41). Toda vez que ellas demás de enfrentar las dificultades de los ciudadanos en general, deben superar barreras propias de una sociedad patriarcal, donde se concibe el papel de la mujer ligado a labore domésticas: la educación tiene que ser accesible a las mujeres y desde esta se debe fomentar la cultura de la no discriminación.

- Tener en cuenta al educar sobre la democracia las diferentes problemáticas globales como las crisis en que la globalización de la economía liberal ha puesto a los estados nacionales y su capacidad de decisión, y desde allí formular propuestas dar poder decisorio a las personas. "Más que buscar comprender el concepto de democracia en el constitucionalismo contemporáneo, hay que intentar vivenciarlo en el ejercicio diario de la ciudadanía" (GORCZEVSK; MULLER, 2010, p. 15-30).

\section{CONCLUSIONES}

El desarrollo histórico ha mostrado la importancia que tiene el ciudadano no solamente como titular de derechos y obligaciones dentro de una organización estatal, sino como un verdadero sujeto político capaz de cambiar transformar las realidades que atentan contra su dignidad alzando su voz de protesta y manifestando toda su potencia.

Así, la ciudadanía examinada en la actualidad se encuentra frente a retos que no solo quieren reducir el espectro de sus derechos reconocidos sino su potencial. Esto mediante la implementación de políticas estatales destinadas a precarizar las condiciones de tal manera que no quede alternativa que someterse a las nuevas reglas. 
Por su parte la educación ha mostrado ser una herramienta importante de las sociedades que guía en la apropiación de una serie de valores dándoles sentido dentro de la sociedad, por ello su manipulación o prestación con enfoque de derechos humanos influye de manera relevante en el futuro de la sociedad.

En ese sentido, la ciudadanía solamente se puede empoderar a través de la educación, lo que implica varios retos, en países en vías de desarrollo, se ven enfrentados a mejorar las condiciones en que presta el servicio educativo para que estas sean accesibles, asequibles, adaptables y aceptables por lo menos en los niveles básicos establecidos en la normatividad nacional e internacional; así como, ocuparse de los contenidos educativos que den un nuevo sentido de la ciudanía enfrentado los desafíos actuales, por ello se requieren una formación en la ciudadanía abierta a las demás culturas con un al sentido de tolerancia e inclusión, que conoce sus derechos y es capaz de revalidarlos a través de los diferentes espacios establecidos en el regímenes democráticos.

\section{NOTAS}

1 La Constitución de 1791, establecía "Nadie podrá ser nombrado elector si no reúne las condiciones necesarias para ser ciudadano activo, a saber: - En las ciudades por encima de seis mil almas, ser propietario o usufructuario de un bien evaluado atendiendo a los registros de contribución en una renta igual al valor local de doscientas jornadas de trabajo o ser arrendador de una habitación evaluada, por los mismos registros, en una renta igual al valor de ciento cincuenta jornadas de trabajo; - En ciudades por debajo de seis mil almas, ser propietario o usufructuario de un bien evaluado atendiendo a los registros de contribución en una renta igual al valor local de ciento cincuenta jornadas de trabajo o ser arrendador de una habitación evaluada, por los mismos registros, en una renta igual al valor de cien jornadas de trabajo; y en el campo, ser propietario o usufructuario de un bien evaluado atendiendo a los registros de contribución en una renta igual al valor local de ciento cincuenta jornadas de trabajo o ser arrendador o aparcero de bienes evaluados, según los mismos registros, al valor de cuatrocientas jornadas de trabajo; - Con respecto a quienes sean al mismo tiempo propietarios o usufructuarios, de una parte, y arrendadores y aparceros, de otra, sus facultades, en atención a estos diferentes títulos, se acumularán hasta el porcentaje necesario para establecer su elegibilidad"

2 En países como Colombia el voto censitario estuvo presente en las cartas de Colombia de 1821 y 1830, Venezuela de 1830 y Ecuador de 1830.

3 Por ejemplo en Estados Unidos los afroamericanos consolidaron su derecho al voto con la "voting rigths act" de 1965 y como consecuencia de las protestas pacíficas lideradas por Martin Luther King.

4 Un ejemplo de ellos fueron las declaraciones del Sergio Berni quien como Ministro de Defensa de Argentina manifestó en octubre de 2014: "Estamos rodeados de delincuentes extranjeros". Según lo registran varios medios de comunicación entre ellos la nación, en noticia disponible en http://www. lanacion.com.ar/1739331- sergio-berni-estamos-infectados-de-delincuentes-extranjeros

5 En Latinoamérica también sucedió en ese sentido, luego de logra la independencia, la educación fue utilizada como una herramienta para la creación también de identidades en torno a héroes representados en los libertadores (CASASSUS, 2003, p. 29-33)

6 El tránsito de monarquías absolutas a Estados Modernos incorporo elementos para el fortalecimiento de una nacionalidad como unidad, dentro de los cuales se encuentran la exaltación de los relatos históricos y la creación de símbolos comunes como el himno y la bandera con el propósito de crear un vínculo con el Estado y susnormas 
7 No obstante debe reconocerse que el pensamiento de la iglesia, especialmente de la protestante influyó en el pensamiento capitalista (PECES-BARBA, 2007, p. 80-81) que se va a convertir en el complemento de la ideología liberal incorporada en los Estados liberales.

8 Con cartas como la de México de 1917 y Weimar de 1919.

9 Es importante anotar que el flujo de la migración es resultado también de la globalización del sistema económico ya que como hemos dicho, la doctrina de la austeridad del Estado y falta de intervención tiene entre algunas de sus consecuencias la falta de oportunidades. De allí que las personas marginadas por parte del Estado se aventuran a buscar oportunidades en otros países.

\section{Referencias Bibliográficas}

BAUMAN, Z. El desafío ético de la globalización. El país [online] Disponible en $<$ http://elpais.com/diario/2001/07/20/opinion/995580025_850215.html > [Acceso 30 de marzo de 2015].

BAUMAN, Z. La globalización: consecuencias humanas, México: F.C.E. 1999.

BARZELATTO, A.; VERDUGO, M. Manual de derecho político. Las fuerzas políticas y los regímenes políticos. Tomo II. 3ª Ed. Santiago: Editorial Jurídica de Chile, 2011.

BUITRAGO, F. L. La doctrina de Seguridad Nacional: materialización de la Guerra Fría en América del Sur. Revista de estudios sociales, 15, p. 74-87, 2003.

CASASSUS, J.. La escuela y la desigualdad. Santiago de Chile: LOM, 2003.

CHOMSKY, N. El sistema de los 500 años y el nuevo orden mundial. En: Chomsky, N. et al. El nuevo Orden Mundial o la conquista de lo interminable. Navarra: Taxalaparta, 1991, p. 15-37.

CHOMSKY, N. Democracia y mercados en el nuevo orden mundial. En: Chomsky, N. y Dieterich H., La sociedad global: Educación, mercado y democracia. Buenos Aires: Oficina de Publicaciones de la Universidad de Buenos Aires, 1996, p. 17-43.

CONTIPELLI, E. Libertad de religión y laicidad en materia electoral: ponderaciones comparadas. [online]. Disponible en <http://portales.te.gob.mx/observatorio/sites/ default/files/sentencias/Libertad,\%20Religi\%C3\%B3n\% 20y\%20Laicidad\%20Ernani\%20 Contipelli\%202013.pdf $>$. [Acceso: 16 de agosto de 2014].

CONTIPELLI, E; PICCIAU, S. La evolución de los modelos de cooperación internacional y las potencias emergentes: BRICS. Revista Dereito Mackenzie, 8 (1), 2014, p. 24-38.

DIAZ MULLER, L. América Latina: Derechos sociales y Desarrollo. Revista del instituto de Ciencias Jurídicas de Puebla, 18. 2006. p. 120- 133.

FERNÁNDEZ, B. Educación popular, derechos humanos y ciudadanía intercultural. La Piragua. Revista Latinoamericana de Educación y Política. 28 (1). 2008 p. 101-109. 
GORCZEVSKI, C.; MULLER, C. El (re) surgimiento de un concepto: la búsqueda del verdadero sentido de la democracia en la sociedad contemporánea. Estudios constitucionales. 8(2). 2010. p. 15-30

JULIOS-CAMPUZANO, A. La globalización ilustrada: ciudadanía, derechos humanos y constitucionalismo. Madrid: Dikynson. 2003.

LEIS, R. La Educación Popular en Derechos Humanos y la construcción del sujeto democrático. Revista Decisio, 10. , 2005.p. 3945.

MAGENZO, A. Pedagogía Crítica en la Educación en Derechos Humanos. Revista Pedagógica Crítica, 2, p. 19-27. 2003.

MICHINEL M. El derecho internacional privado en los tiempos hipermodernos. Madrid: Dykinson, 2012.

MEJÍA, M.; DELGADO, M.; VALVERDE Y. Educación para una ciudadanía global. Revista Fedumar Pedagogía y Educación, 1 (1). 2014. p. 17-24.

NINA, A. La doctrina de seguridad nacional y la integración latinoamericana. Nueva sociedad, (27), 33-50. 1979.

OBSERVATORIO PROGRAMA PRESIDENCIAL DE DERECHOS HUMANOS Y DIH. 2009. Derechos Económicos Sociales y Culturales. El desafío de la ciudadanía Social. Bogotá: Impresol.

ORTIZ E. El fin de la guerra fría y el nuevo orden mundial. Revista de estudios internacionales, 137. 2002. p. 123-125.

PECES BARBA, G. Educación para la Ciudadanía. En Fundación Asturias Y UGT Asturias Eds. $8^{\text {a }}$ Escuela internacional de verano. Seguridad Vs. Libertad. Asturias: Edicom. , 2007. p. 73- 90 Ponce, A., 1973. Educación y la lucha de clases. Medellín: La Pulga LTDA

ROIG-IBAÑEZ, J. La educación ante un nuevo orden mundial: diagnósticos y reflexiones en torno a los nuevos problemas que le plantea el nuevo ordenamiento mundial. Madrid: Díaz de Santos. 2006.

TEDESCO J. C. La Educación en el Marco del Nuevo Capitalismo. En: Memorias del II Congreso Nacional de Educación Superior a Distancia. Educación en la Globalización. [online] Disponible , 2001 en http://www.derechoshumanos.unlp.edu.ar/assets/files/ documentos/la-educacion-en-el-marco-del- nuevo-capitalismo-juan-carlos-tedesco.pdf [Acceso 30 de marzo de 2015].

TOMASEVSKI, K., 2004. El asalto a la educación. España: Intermón Oxfam. 


\section{Resumen}

En el siguiente trabajo se analiza la concepción de ciudadanía abordándola de manera histórica y confrontándola con un análisis de las diferentes hegemonías que han tratado de imponer un orden global y las consecuencia de la aplicación de políticas en obediencia a dicho orden. Luego de ello, revisa el derecho a la educación teniendo en cuenta las nuevas realidades globales para, finalmente, centrar el estudio en las diferentes problemáticas que afronta la educación como consecuencia del orden mundial y proponer un enfoque sobre el cual debería guiarse.

Palabras-clave: Ciudadanía. Orden Global. Derecho a la educación. 


\section{EDUCAÇÃO PARA A CIDADANIA NA NOVA ORDEM MUNDIAL}

\section{Resumo}

No seguinte trabalho, analisa-se a concepção da cidadania fazendo uma abordagem histórica e confrontando-a com uma análise das diferentes hegemonias que tentaram impor uma ordem global e as consequências da aplicação de politicas em obediência a mencionada ordem. Posteriormente, verifica-se o direito à educação levando em consideração as novas realidades globais, para, finalmente, concentrar o estudo nas diferentes problemáticas enfrentadas pela educação como consequência da ordem mundial e propor uma abordagem, na qual, ela deve ser guiada.

Palavras-chave: Cidadania. Ordem Global. Direito à educação. 


\title{
EDUCATION FOR THE CITIZENSHIP IN THE NEW WORLD ORDER
}

\begin{abstract}
In the following work is analyzed the conception of citizenship, making a historical approach and confronting it with the analisys of the different hegemonies that try to impose a global order and the consequences of the application of policies in obedience to the mentioned order. After, is verified the right to education taking into account the new global realities, for, finally, concentrate the study in the different problematics faced by the education as a consequence of the world order and propose an approach, in what, it must be guided.
\end{abstract}

Keywords: Citizenship. Global Order. Right to education. 